\title{
Secondary IRCT (Chronic End-Stage Renal Disease) for Aminoglycosides
}

\section{INH Bekhti ${ }^{1}$, H Zitouni ${ }^{1}$, K Djouded ${ }^{2}$, FZ Mekaouche ${ }^{1}$, H Fetati ${ }^{1}$, F Boudia ${ }^{1}$ and H Toumi $^{\text {* }}$}

${ }^{1}$ Pharmacovigilance service, EHUO, Algeria

${ }^{2}$ Nephrology service, EHUO, Algeria

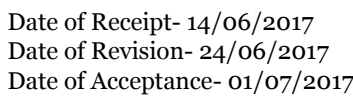

Date of Receipt- 14/06/2017

Date of Revision- 24/06/2017

Date of Acceptance- 01/07/2017

\section{Address for \\ Correspondence}

Pharmacovigilance Laboratory,

Algerian Democratic and

Popular Republic Health and

Higher Education Ministry,

University of Oran, Es Senia,

Algeria

E-mail: toumi54@live.fr

\begin{abstract}
The adverse renal effects of aminoglycosides are increasing, up to $20 \%$ in patients treated with this class of antibiotic, nephrotoxicity is manifested by the renal insufficiency with a variable degree, usually clinically silent but the return to the former state is not always obtained which progresses towards chronic kidney disease. After studying a declaration of an adverse case at the pharmacovigilance service of the UHE of Oran.The impact of nephrotoxicity of aminoglycosides in the aggravation of pre-existing renal insufficiency has been demonstrated according to the French and Anglo-Saxon method of accountability that is why information on pharmacological therapeutic monitoring of STP should be recommended. In conclusion, the knowledge of the factors favoring the nephrotoxicity of aminoglycosides, the respect of the dosages and the reduction of the duration of the treatment allows the practitioner to take measures in order to prevent and to reduce the frequency of the renal complications.
\end{abstract}

The side effect of aminoglycoside therapy may occur in up to $20 \%$ of the exposed patients treated with this antibiotic class, this nephrotoxicity is manifested by varying degrees of renal insufficiency (IR), usually clinically silent but the return to the previous state is not always got, sometimes progress to chronic renal disease. Following the study of a case of adverse reaction reporting; has been shown by the French and Anglo-Saxon method of accountability, the impact of aminoglycosides' nephrotoxicity in the aggravation of existing IR, why therapeutic drug monitoring TDM actualities are recommended. In conclusion, knowledge of predisposing factors nephrotoxicity of aminoglycosides, respect the doses and reducing the duration of treatment allows the practitioner to take measures in order to prevent and decrease the frequency of renal complications.

Keywords: Aminoglycosides, Nephrotoxicity, Accountability, Therapeutic, Frequency.

\section{INTRODUCTION}

Renal involvement of iatrogenic origin is a common occurrence in clinical practice and is often poorly understood. This is a serious event that is associated with significant morbidity and mortality ${ }^{1-3}$.

Aminoglycosides are widely used antibiotics; their major risk is the nephrotoxicity following the accumulation leading to a tubular necrosis.

The adverse renal effects of aminoglycosides are increasing up to $20 \%$ in patients treated with this class of antibiotic; nephrotoxicity is manifested by the renal insufficiency with a variable degree ${ }^{4}$.
The objective of this work is to demonstrate the impact of nephrotoxicity of aminoglycosides in the aggravation of a pre-existing renal failure, following the study of a case of adverse reaction.

\section{METHODS}

Patient A. N., weighing $75 \mathrm{~kg}, 35$ years old, admitted to the nephrology service of EHUO (Renal Transplant Unit) for a kidney transplant. This patient had moderate renal insufficiency (IR) with severe anaemia.

Following a high CRP and VS and no antibiogram, a probabilistic treatment of a urinary tract infection was 
based on aminoglycoside. In fact, the patient took 160 $\mathrm{mg}$ of gentamicin with two intramuscular injections per day $(2.133 \mathrm{mg} / \mathrm{kg} / \mathrm{d})$ for eight days.

The infection persisted and the clinician introduced netromicin ${ }^{\circledR}$ (netilmicin), two $150 \mathrm{mg}$ injections (4 $\mathrm{mg} / \mathrm{kg} /$ day). She took in parallel folic acid, doxycycline, cefalexin, metronidazole, omeprazole, tardyferon, bicarbonate and magnesium. The patient was diagnosed with chronic end-stage renal insufficiency (IRCT), plasma creatinine at $90 \mathrm{mg} / 1$ corresponds to a creatinine clearance of $12.15 \mathrm{ml} /$ min according to Cockcroft; $7.17 \mathrm{ml} / \mathrm{min}$ MDRD and $6.81 \mathrm{ml} / \mathrm{min}$ CKD-EPI, requiring dialysis sessions.

The causality assessment was analyzed with the French and the Anglo-Saxon methods.

The French method was first devised in 1978 (Dangou-mau et al.), revised in 1985 (when it was published simultaneously in French and English) (Begaud et al.). It is the only imputability method to have legal statu. It is probably one of the most widely used, if not the most widely used.

Imputability method, having been applied to more than 100000 reports, and yet it remains widely misunderstood.

The French method is algorithmic, and is based on the evaluation of eight criteria divided into three groups: chronology, semiology and bibliographic data. Seven criteria enable the establishment of a chronological score (C) and a semiological score (S), which, once combined, yield the "Intrinsic" causality score (I), which is allocated on the sole basis of the case of adverse reaction considered.

The eighth criterion, which is the known potential of the drug to generate an adverse reaction, is used to derive an "extrinsic" or bibliographic score (B) for the reaction from a categorization of the scientific literature available for the drug or adverse reaction association.

The Naranjo algorithm, Naranjo Scale, or Naranjo Nomogram is a questionnaire designed by Naranjo et al. for determining the likelihood of whether an adverse drug reaction is actually due to the drug rather than the result of other factors.

Probability is assigned via a score termed definite, probable, possible or doubtful.

\section{RESULTS}

The accountability study of the two aminoglycosides, according to the French method, shows an intrinsic accountability score at I4, which means very likely,
(Tables 1-3). Similarly, the well-known welldescribed effect of the two drugs leads to an extrinsic B3 accountability.

When evaluating according to the Anglo-Saxon method, estimates that aminoglycosides are probably responsible for this effect (with a score of +8 ).

\section{DISCUSSION}

Often kidney failure occurs after the discontinuation of the treatment, which may ignore the responsibility for aminoglycoside. Renal impairment is usually acute, reversibility is not always obtained, and some of it progress towards chronic renal disease: lesions of interstitial fibrosis are frequently observed on the renal histological examination and it can lead to chronic end-stage renal insufficiency ${ }^{2}$, and this is the case of our patient ${ }^{11}$.

The prevalence of nephrotoxicity due to aminoglycosides varies between 7 and $20 \%$ of patients treated with this class of antibiotic. The percentage of patients who develop renal insufficiency increases with the duration of exposure, reaching 50\% after 14 days of treatment ${ }^{2,12,13}$. The mechanism of toxicity is related to a direct dose-dependent cytotoxic effect due to the excessive accumulation of these drugs in the renal cortex. Schematically, the aminoglycosides are filtered in a non-metabolized form and reabsorbed by the renal tubules. After its fixation on the phospholipid membrane receptors, they penetrate into the tubular cells where they induce structural or functional modifications (inhibition of phospholipases, release of free radicals, anomaly of mitochondrial function, etc.) leading to cell death. This accumulation is also correlated with the residual serum concentrations of aminoglycoside ${ }^{14,15}$.

Gentamicin penetrates into the tubular cell via the megaline multi-ligand of the receptor and then the absorption takes place through a clathrin-coated pit (Figure 1), it passes through the lysosomes, the Golgi apparatus and Endoplasmic reticulum in the cytoplasm where it forms complexes with iron that catalyze the formation of reactive oxygen species (ROS). In the lysosome, gentamicin causes the release of pro-apoptotic cathepsins and, in the endoplasmic reticulum, the release of Von Hippele Lindau binding protein 1 (VBP1). Either directly or indirectly (via ROS), it causes the release of cytochrome $\mathrm{C}$ from the mitochondria, a key step in apoptosis. It may have intracellular effects without actually entering the cell by quickly increasing the intracellular $\mathrm{Ca}^{2+}$ concentration and then increasing the anti-apoptosis and pro-proliferative signals Akt and $\mathrm{Erk}^{16}$. 
This nephrotoxicity is usually clinically silent. Polyuria, due to a lack of concentration of urine, may be one of the early signs. It is the elevation of blood urea and creatinine which asserts the renal involvement, which usually appears between the fifth and the eighth day of treatment ${ }^{12}$.

Currently, renal damage can be detected earlier by recent labeling techniques such as the determination of lysosomal enzymes in urine released by the brush border of the injured proximal tube, the main target of excessive and prolonged concentration of The aminoglycoside at the tubular cell.

In this case, the renal complication is the consequence of three factors potentiating its occurrence. The use of this therapeutic class without taking account of the fragile terrain, pre-existent IR, inadequate dosage and the role of associated drugs, also very important to consider, emphasizing the more or less dangerous associations of two nephrotoxic drugs.

It's known that gentamicin forms complexes with mitochondrial $\mathrm{Fe}+2$ to catalyse the formation of free oxygen radicals, but the physician have prescribe Iron only to treat anemia.

\section{TDM Practical Recommendations According Pharmacokinetics Unit Pharmacovigilance Laboratory EHUO}

The respect of dosage, reducing the duration of treatment (up to four to five days), the adequate hydration, close monitoring of residual drug levels and administration of a single daily dose (DUJ) are the most effective means to prevent the nephrotoxicity of the aminoglycosides.

Indeed, a single administration of the drug results in a very high peak of plasma and urinary concentrations that exceeds the reabsorption capacity of the proximal tubule (Figure 2) so that most of the drug is excreted and is not reabsorbed by the tubular cells. Conversely, if the dose of the drug is fractionated, the tubular reabsorption is not limited and the recovery of the drug by the proximal tubular cells is more significant.

In patients with renal insufficiency, the dose should be adjusted according to creatinine ratio and the value of creatinine clearance, so the gentamicin should be used at a dose of $1 \mathrm{mg} / \mathrm{kg}(75 \mathrm{mg})$, the netilmicin at 2 $\mathrm{mg} / \mathrm{kg}(150 \mathrm{mg})$, every 72 hours $^{14}$.

The serum dosage performed one hour after intramuscular injection or within 30 minutes following intravenous infusion determines the peak (C max). The latter must be $5-10 \mu \mathrm{g} / \mathrm{ml}$ in DUJ and between $5-12 \mu \mathrm{g} / \mathrm{ml}$ in fractionated form. Whereas the residual concentration ( $\mathrm{C} \mathrm{min}$ ) before the new injection should be in DUJ $<0.5 \mu \mathrm{g} / \mathrm{ml}$ and $<2 \mu \mathrm{g} / \mathrm{ml}$ in fractionated form.

\section{CONCLUSION}

In order to reduce the incidence of end-stage renal disease, it is necessary to prevent the occurrence of the nephrotoxic effects with iatrogenic origin and it should be at the forefront because they can be the subject of a genuine primary prevention. Patients with chronic renal failure have a high risk of escalating quickly to an end-stage renal disease when either drug class exerts a nephrotoxic effect.

As far as a patient treated with an aminoglycoside is concerned, the prevention of superadded nephrotoxicity requires the plasma dosage of the aminoglycoside and it's monitoring during the course of treatment, knowing that it should be as short as possible with the weaker dosage.

Although aminoglycosides are excellent antibiotics, they are no longer the only ones to be effective in infections where their prescription has been specific in a long time. Primary prevention in patients with risk requires the use of non-nephrotoxic antibiotics for comparable efficacy, hence antibiogram interest.

Secondary prevention of end-stage renal insufficiency in patients with drug-induced nephrotoxicity involves discontinuation of the drug in question. The need to continue treatment is an exceptional circumstance.

\section{REFERENCES}

1. Montie T, Patamasucon P. Aminoglycosides: The complex problem of antibiotic mechanisms and clinical applications. Eur J Clin Microbiol Infect Dis. 1995;14:85-7.

2. Lortholary $\mathrm{O}$, Tod $\mathrm{M}$, Cohen $\mathrm{Y}$, et al. Aminoglycosides. Med Clin North Am. 1995;79:61-87.

3. Hock R, Anderson RJ. Prevention of drug induced nephrotoxicity in the intensive care unit. J Crit Care. 1995;10:33-43.

4. Choudhary D, Ahmed Z. Drug induced nephrotoxicity. Med Clin North Am. 1997;81:70517.

5. Gilbert DN. Once daily aminoglycoside therapy. Antimicrob Agents Chemother. 1991;35:399-405.

6. Galloe AM, Graudal N, Christensen HR, et al. Aminoglycosides: Single or multiple daily dosing? Meta-analysis on efficacy and safety. Eur J Clin Pharmacol. 1995;48:39-43. 
7. Ali MZ, Goetz MB. A meta-analysis of the relative efficacy and toxicity of aminoglycosides. Clin Infect Dis. 1997;24:796-809.

8. Thomson AH, Duncan N, Silverstein B, et al. Antimicrobial practice. Development of guidelines for gentamicin dosing. J Antimicrob Chemother. 1996;38:885-93.

9. Edson RS, Terrell CL. The aminoglycosides. Mayo Clin Proc. 1991;66:1158-64.

10.Keller F, Burner K, Schwartz A, et al. Therapeutic aminoglucoside monitoring in renal failure patients. Ther Drug Monit. 1987;9:148-53.

11. Kirkpatrick CM, Duffull SB, Begg EJ. Pharmacokinetics of gentamicin in 957 patients with varying renal function dosed once daily. $\mathrm{Br} \mathrm{J}$ Clin Pharamcol. 1999;47:637-43.

12.Herrero A, Rius Alarco F, Garcia Diez JM, et al. Pharmacokinetics of netilmicin in renal insufficiency and hemodialysis. Int $\mathrm{J}$ Clin Pharmacol Ther Toxicol. 1988;26:84-7.
13.Pea F, Viale P, Pavan F, et al. Pharmacokinetic considerations for antimicrobial therapy in patients receiving renal replacement therapy. Clin Pharmacokinet. 2007;46:997-1038.

14.Dager WE, King JH. Aminoglycoside in intermittent hemodialysis: Pharmacokinetics with individual dosing. Ann Pharmacother. 2006;40:914.

15.Teiger MM, Duffull S, Dang L, et al. Dosing of gentamicin in patients with end stage renal disease receiving hemodialysis. J Clin Pharmacol. 2006;46:1259-67.

16.Aronoff GR, Bennett WM, Burns JS, et al. Drug prescribing in renal failure: Dosing guidelines for adults and children. 5th ed. American College of Physicians, Philadelphia. 2007. 
Table 1. Chronological and evolving criteria of the intrinsic accountability according to the French method

\begin{tabular}{|c|c|c|c|c|c|c|c|c|}
\hline \multirow{2}{*}{ Drug administration } & \multicolumn{7}{|c|}{ Appearance time limit of the event } \\
\cline { 2 - 9 } & \multicolumn{7}{|c|}{ Very suggestive } & \multicolumn{7}{c|}{ Compatible } & Incompatible \\
\hline \multirow{2}{*}{ Drug discontinuation } & Drug re-administration \\
\hline Suggestive Evolution & C3 & R0 & C3 & R- & R + & R0 & R- & \\
\hline Non-conclusive Evolution & C3 & C2 & C1 & C3 & C2 & C1 & C1 & C0 \\
\hline Non-suggestive Evolution & C1 & C1 & C1 & C1 & C1 & C1 & C0 \\
\hline
\end{tabular}

Table 2. Semiological criteria of the intrinsic accountability according to the French method

\begin{tabular}{|c|c|c|c|c|c|c|}
\hline Semiology (clinical et paraclinical) & \multicolumn{4}{|c|}{$\begin{array}{l}\text { The role of this drug (and / or very well- } \\
\text { validated factor) }\end{array}$} & \multicolumn{2}{|c|}{$\begin{array}{l}\text { Other non-semiotic } \\
\text { contingencies }\end{array}$} \\
\hline \multirow{2}{*}{ Non-medication explanations } & \multicolumn{6}{|c|}{ Reliable Specific Exams (L) } \\
\hline & $\mathrm{L}(+)$ & $\mathrm{L}(0)$ & $\mathrm{L}(-)$ & $\mathrm{L}(+)$ & $\mathrm{L}(0)$ & $\mathrm{L}(-)$ \\
\hline Absence & S3 & S3 & $\mathrm{S} 1$ & S3 & S2 & $\mathrm{S} 1$ \\
\hline Possible & S3 & S2 & $\mathrm{S} 1$ & S3 & S1 & $\mathrm{S} 1$ \\
\hline
\end{tabular}

Table 3. Intrinsic accountability score

\begin{tabular}{|c|c|c|c|}
\hline & \multicolumn{3}{c|}{ Semiology } \\
\hline Chronology & S1 & S2 & S3 \\
\hline C0 & I0 & I0 & I0 \\
\hline C1 & I1 & I1 & I2 \\
\hline C2 & I1 & I2 & I3 \\
\hline C3 & I3 & I3 & I4 \\
\hline
\end{tabular}

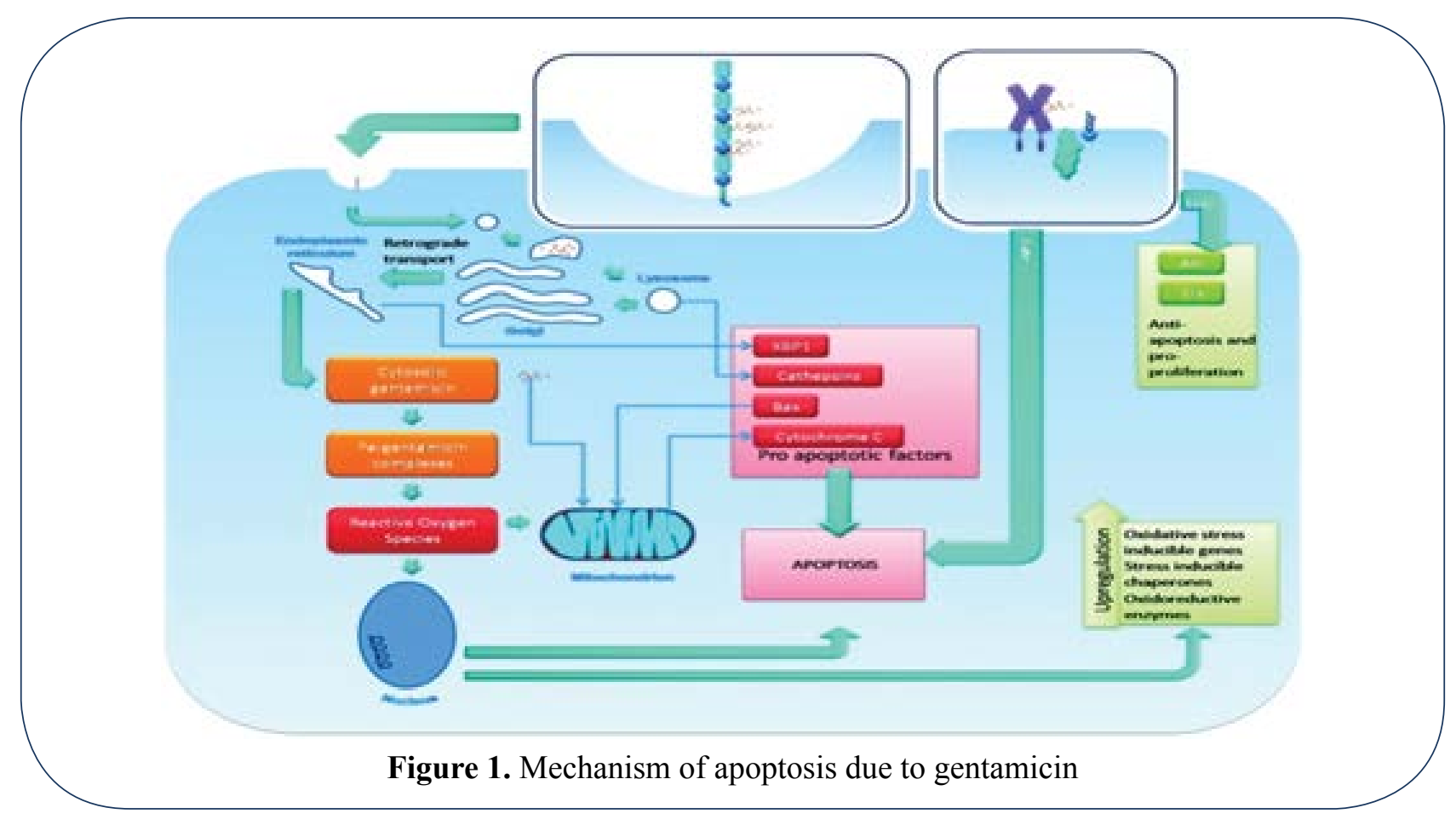




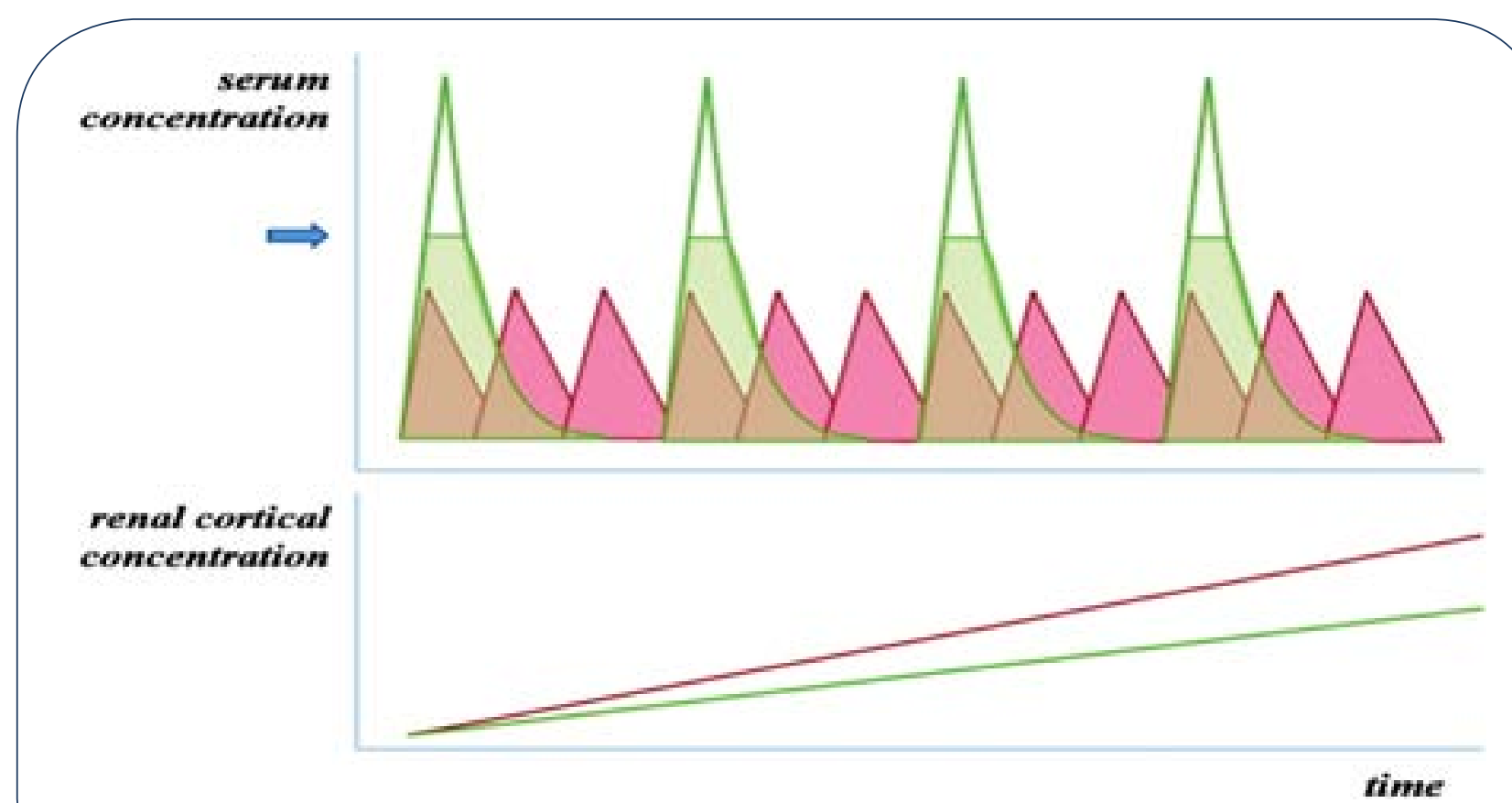

Figure 2. Saturability and accumulation of aminoglycosides in the fractional dose (DF) against the daily single dose (DUJ) 